\title{
The Development and Evaluation of an Electronic Health Record Efficiency Workshop for Providers
}

\author{
Kara Scott ${ }^{1}$ Elizabeth Hathaway ${ }^{1}$ Karen Sharp ${ }^{1}$ Paula Smailes ${ }^{1}$ \\ ${ }^{1}$ Department of Information Technology, The Ohio State University \\ Wexner Medical Center, Health System Informatics, Training and \\ Address for correspondence Paula Smailes, DNP, RN, Department of \\ Information Technology, The Ohio State University Wexner Medical \\ Center, 630 Ackerman Road, Suite F2033, Columbus, OH 43202, \\ United States (e-mail: paula.smailes@osumc.edu).
}

Appl Clin Inform 2020;11:336-341.

\begin{abstract}
Keywords

- physician

- efficiency

- satisfaction

- training

- education

Background The electronic health record (EHR) has historically been known to be a source of stress and dissatisfaction, leading to reduced efficiency and productivity for providers. This issue is complicated by constant changes in EHRs that are necessary to keep systems current with evolving functionality. Knowing the existence of this problem, an evidenced-based solution, known as an efficiency workshop, was developed by our information technology training and optimization team for providers as a means of ongoing professional development.

Objectives The objectives of this project were to identify EHR optimization needs for providers in various clinical departments and improve their EHR satisfaction. The development of a program focused on provider efficiency tools and personalization was key and, once piloted, how to measure program success.

Methods Efficiency workshops comprised members of the IT training team who set up on site training sessions during reserved time with providers during departmental meetings. Sessions focused on reviewing EHR efficiency tools using demonstration of existing system functionality. Participating providers were given continuing medical education (CME) credits upon completion of evaluations used as a quality improvement tool for the program.

Results Descriptive results showed that providers were satisfied with this method of EHR instruction. Subjective feedback yielded positive themes such as informative, well done, organized, and helpful.

Conclusion This initiative began as a pilot program and successfully expanded across clinical departments at our academic medical center. Future plans are to sustain and further invest in this program by using EHR reporting features to further customize these sessions and evaluate impact on system use.
\end{abstract}

\section{Background and Significance}

The electronic health record (EHR) is one of the most essential tools used in health care today. However, despite the necessity of its use, it can be a documentation burden. It has been shown that use of the EHR can lead to negative consequences to providers, such as stress and burnout, ${ }^{1-9}$ while causing impact with organizational issues that hinder patient care and productivity. ${ }^{10}$ Specific areas of the EHR identified as contributing to this burden include data entry, discrete data elements, reporting, workflows, interoperability, design engineering, and the in-basket. $2,11,12$ received

January 9, 2020

accepted after revision

March 8, 2020 (c) 2020 Georg Thieme Verlag KG Stuttgart · New York
DOI https://doi.org/ 10.1055/s-0040-1709509. ISSN 1869-0327. 
The initial transition to an EHR for providers can be challenging. One study showed that when transitioning to an EHR system in an ambulatory setting, physician productivity decreased as measured by relative value units (RVUs) and clinic volumes during the year following implementation. ${ }^{13}$ This was affirmed by Scott et al ${ }^{14}$ who showed that, 2 months after EHR implementation, providers were spending twice as much time documenting patient encounters and reduced time interacting with patients. Evidence has shown that physician productivity improves with the number of years' experience with an EHR. ${ }^{15}$ However, even for those who have experience, constant system changes create an ongoing challenge and prohibit mastery of all system features. It is a very real scenario that once providers become knowledgeable with patient care workflows in the EHR, they may need to constantly relearn the system due to ongoing system change.

\section{Role of Provider Electronic Health Record Training}

The process of onboarding new providers in any organization should include EHR training. Training expands beyond basic computer usage and may incorporate organizational workflows and policies. Improvement in EHR confidence and efficiency have been shown to be possible outcomes of training. ${ }^{16,17}$ However, in a study by Rathert and colleagues, ${ }^{18}$ participants felt that training was insufficient with EHRs that posed a subsequent barrier to care coordination and communication. Upon hire, initial training must not only be retained to memory but ongoing training for routine system updates and upgrades is necessary, as the systems are further enhanced.

Because the EHR is not stagnant, organizations need to consider continued communication and training following initial implementation or new hire training. ${ }^{18,19}$ EHR optimization, or the assisting end users with optimal system usage, is essential for clinician success. To this point, one organization conducted a pilot program using one-on-one EHR support for its physicians. It showed that those who completed individualized sessions spent approximately 25 fewer hours per month working in the EHR system, along with a $12 \%$ increase in satisfaction and $24 \%$ increase in efficiency. ${ }^{1}$ Using a similar approach, another study found increased EHR confidence with $98 \%$ of providers reporting improved efficiency. ${ }^{16,20}$ Furthermore, it has been suggested that the following several characteristics may contribute to physician satisfaction with the EHR: 6 hours or more of initial training, several hours or more of ongoing training, organizational culture, and system personalization. ${ }^{21}$

\section{Challenges of System Change at an Academic Medical Center}

When our organization first went live with the EHR, instructor-led training (ILT) in a computer laboratory served as the initial exposure to the system. This training method evolved in 2015 into electronic-learning (e-learning) modules. The self-paced format of e-learning was shown be a provider satisfier, allowing those who are familiar with an epic-based system to move quickly and those unfamiliar to take more time. The e-learnings are also a source of reference should the need arise to review content. While this initial training is essential for onboarding physicians, it became apparent that EHR optimization was just as important. Optimization involves on site EHR support for end users that promotes optimal use of the system.

While providers may struggle to keep up with ongoing system change, they are not the only ones. Information technology (IT) training teams can be challenged with training and optimization of EHR changes to thousands of providers across multiple locations within academic medical centers (AMC). They must ensure end user proficiency that ultimately results in the delivery of quality patient care. Communication of changes also becomes critical, but the most effective channel to deliver this information remains an ongoing struggle. E-mail messages, presentations, newsletters, and super user sessions are used but may not reach every provider. Finding the best method for communication and education remains an evolving process.

\section{One-on-One Support}

As an option for additional provider support, our AMC used an EHR coaching session that was historically offered by the IT training and optimization (T\&O) team. Evidence has shown that one-on-one support is effective for EHR adoption. ${ }^{20}$ A specific e-mail address was created, so that requests could come to the coach mail, and a calendar was established by the training team to manage staff-provider time. During these sessions, a provider who is struggling or wants to be more efficient will spend time with a member of the IT T\&O team. The IT trainer would work with the provider either on specific EHR functionality or workflow efficiencies pertaining to features such as orders, messages, and documentation. This approach was very effective but limited by the trainerprovider ratio. One provider coach and two ambulatory trainers were responsible for over 1,000 physicians.

While additional staff members were added to the IT T\&O team, it was still not enough to reach the plethora of providers who could use more support. Many of our providers who were here prior to our EHR implementation last had training over 8 years ago with no formal training since. It is cost-prohibitive to remove providers from patient care for EHR training, yet the value of EHR knowledge is recognized. There was a strong desire by the principal provider trainer to reach larger numbers of providers and still provide the same quality of support as a one-on one session.

As this was being developed, one clinical department at our AMC offered its physicians a wide range of wellness opportunities. The service that they wanted most was EHR assistance. This has been found in the literature, whereby annual wellness surveys to providers have revealed the EHR burden placed on them. ${ }^{22}$ The medical director approached the IT T\&O team about providing additional resources to see if a coaching format be done at a faculty meeting. To fill this need, a physician efficiency workshop (EW) was developed as a means of faculty development. The intent was to pilot a 
program with this group, then branch out to additional departments if proven successful.

\section{Objectives}

As a solution to this issue, we set out to build a provider EHR efficiency program that would improve the experience of these end users.

The objectives of this project were as follows:

- Identify EHR optimization needs for providers in various clinical departments.

- Improve provider satisfaction with the EHR.

- Develop an EHR optimization program focused on provider efficiency tools and personalization.

- Determine a how to monitor program success metrics.

\section{Methods}

\section{Pilot Program}

A multitude of tasks were done in preparation of this pilot session. Reports from our Epic-based systems were used to show how physicians in this department were using system functionality. This review of EHR data showed areas of opportunity for both efficiency and personalization. Time was spent on learning more about the department's operations, provider workloads, and common patient conditions. Rooms were booked for several sessions so that the providers were equipped with a computer in the conference room used for the faculty meeting.

The final measure of preparation before initiating the pilot was a meeting with the medical director of this department. This served the purpose of understanding the physician's EHR perceptions to further ascertain what the climate and attitudes were like toward the system. Subsequently, the medical director sent an e-mail to clinical faculty, connecting this to the wellness initiative, and stated the expectation that attendance was required.

The first pilot session had 12 attendees and was scheduled for 1 hour in a conference room. Physicians were asked to bring their own laptops to the session. Challenges occurred with internet connectivity not being optimal. In addition, some providers did not bring their laptop, so the work laptops of IT staff were surrendered to accommodate these users. The session lasted for 1 hour and verbal feedback was positive. The department chair was so enthusiastic, a second session was scheduled with five attendees.

\section{Efficiency Workshops}

After the positive feedback from the pilot session, a decision was made to expand the program. The program was named EW on wheels. As the success of the program was verbally shared among physicians and leaders, more and more clinics and departments were requesting sessions. The EW team did their own marketing at leadership, chair, and faculty meetings to gather interest, as well as new provider orientation and resident coordinators meetings. When interest evolved into scheduling an EW session, managers, administrators, and lead physicians would assist with establishing a date, time, and location.
A program package was developed that is adjusted and repeated for different specialties and groups. Small groups of less than 15 providers were the focus during times of their convenience, be it early mornings, evenings, or lunch time. Hands-on work in the system is critical for success, yet we were challenged to have physicians remember to bring their laptops. The EW team purchased 15 laptops and rolling cases equipped with charging stations to effectively implement a classroom on wheels, which ensured system access for all. As an added incentive, participants of EW earned 2.0 hours toward continuing medical education (CME).

The EW team consists of four to six trainers per session, including one lead trainer and additional T\&O staff to answer questions and allow for individualized support. Trainer specialties exist in a wide variety of workflows such as inpatient, ambulatory, procedural areas, and specialties (cardiology, radiology, women and infant, emergency department, oncology, ophthalmology, orthopaedics, and transplant).

Establishing an agenda is important for each program. Every EW session is tailored to the department's specialty, but the topics are generally the same as mentioned below:

- Tools to quickly find information in the chart.

- Specialty specific documentation tools.

- Messaging and communication tools within the EHR.

- Customized ordering tools.

- Reporting.

End user data are obtained on an ongoing basis from the EHR vendor that shows how much time providers are spending in the EHR and using distinct features. There is an expectation by both the vendor and organizational leadership that this data be used to identify areas of need, focus optimization efforts, and improve provider system use. Prior to EW sessions, this information is reviewed to determine how the department and individual users may be struggling with the system. This allows the EW team to save providers time by targeting the agenda to make them more efficient. This, in turn, increased provider satisfaction. Providers are able to leave these sessions with templates, ordering tools, filters, macros, and other personalization tools in the live system so that they can begin using them immediately.

At the conclusion of each workshop, attendees are sent an email that contains the links to supporting training materials and additional resources. They are also informed of the availability of individual coaching, should the need arise. All workshop trainers are accessible at the physician coach e-mail address. They are also asked to complete a CME evaluation and satisfaction survey to receive CME credit. The survey included a fivepoint Likert scale whereby 1 , strongly disagree; 2 , disagree; 3 , neutral; 4, agree; and 5, strongly agree and nominal data.

\section{Results}

\section{Quantitative Data}

There is a continuous commitment to understand how to measure program effectiveness. To do this, descriptive data from the CME evaluations served as a means for program feedback and continuous quality assurance. Evaluations 
Table 1 Attendees of the efficiency workshop program

\begin{tabular}{|l|l|}
\hline Attendee & Total \\
\hline Physician & 70 \\
\hline Nurse & 6 \\
\hline Health care professional & 12 \\
\hline No response & 20 \\
\hline Total respondents & 108 \\
\hline
\end{tabular}

were reviewed from January 2018 to September 2019 and obtained from our organizational CME department. A total of 129 respondents completed CME evaluations for the program. While these sessions were focused on providers, other health care roles attended these sessions. Of the 108 who responded to the question, $65 \%$ identified themselves as physicians (-Table 1 ).

Overall, participants reported a positive impact on their practice (-Table 2). The majority of participants found no evidence of commercial bias or influence on the program, as well as feeling as though they received enough information to bring about practice change in how they cared for patients (-Table 3). Lastly, a 10-point Likert scale was used asking participants, "overall, how satisfied were you with this educational activity?" Of the 117 respondents, 56\% reported that they were extremely satisfied, while another $43 \%$ reporting some level of satisfaction with the program.

\section{Qualitative Data}

In addition to quantifiable information, patients were asked open-ended questions to elicit subjective information about the program. These were classified into the following three

Table 2 Satisfaction questions

\begin{tabular}{|l|l|l|}
\hline Statement & Mean & SD \\
\hline $\begin{array}{l}\text { I have developed new strategies } \\
\text { to address the issues that were discussed }\end{array}$ & 4.62 & 0.78 \\
\hline My ability and skills have been improved & 4.55 & 0.80 \\
\hline $\begin{array}{l}\text { I have identified changes that I will } \\
\text { implement in my practice }\end{array}$ & 4.59 & 0.80 \\
\hline $\begin{array}{l}\text { I expect positive changes in my } \\
\text { patient outcomes }\end{array}$ & 4.43 & 0.78 \\
\hline $\begin{array}{l}\text { The learning objectives of this } \\
\text { activity were achieved }\end{array}$ & 4.59 & 0.78 \\
\hline
\end{tabular}

Abbreviation: SD, standard deviation.

Table 3 Nominal data

\begin{tabular}{|l|l|l|}
\hline Question & Yes (\%) & No (\%) \\
\hline $\begin{array}{l}\text { Was there any evidence of } \\
\text { commercial bias or influence in } \\
\text { the content of the program? }\end{array}$ & 2 & 98 \\
\hline $\begin{array}{l}\text { Do you feel you need more } \\
\text { information before you can change } \\
\text { the way you care for your patients? }\end{array}$ & 26 & 74 \\
\hline
\end{tabular}

groups: impact comments, overall comments relating to satisfaction with the educational activity, and practice problems to be addressed for future sessions. Responses to these questions were categorized into themes for further interpretation.

For impact comments, the most common themes were that the sessions were great, helpful, and provided tools to be more efficient. One attendee commented, "love all the new buttons I was able to create." Another said, "providers and myself have benefitted from this." The structure of the format was praised by some, with one saying, "concise and efficient with explanations." One suggestion for improvement was given that the workshop team, "should have people hold questions until the end."

Overall comments were asked for additional feedback on any aspect of the program. This section repeated the themes for impact comments, that the workshop was organized, helpful, and well done. One participant described the session as, "efficient, focused presentation; thorough, well-explained." Another user stated, "excellent and appreciated." One user was unsure that it would be helpful given a complex patient population. Several people were interested in additional sessions. A participant stated, "(I) want this every quarter, if possible."

Many suggestions were given for possible future workshop sessions. Examples included referral letters, charting office visits, phone encounters, additional customization, communication in patient portals, and learning additional tools to increase efficiency. This feedback is then used by the team for consideration in future program development.

\section{Discussion}

As we began the pilot, it was important to understand the optimization needs of providers before, during, and after workshops. In preparation for events, gathering information about clinical operations and patient populations, through data review and communication with providers, refined the session content. The results showed that providers who attended these sessions were satisfied with this method of EHR optimization and that they felt it had a positive impact on their EHR use. Qualitative feedback supported quantitative data and also directed the program to topics where help was needed.

After the pilot was conducted and several workshops had been completed, we learned more about the most effective structure of these sessions. This included knowing what tools were needed for planning and implementation. One change that evolved was that we began bringing laptops, removing that expectation from the provider. That way we ensured that everyone would have a computer that was connected to the internet and running optimally. Our department invested in this program by purchasing additional laptops specifically for this program that were taken to each session in a rolling cart. Overall, the results show that attendees were pleased with these sessions and in many cases not only were they satisfied, they wanted additional workshops to learn tools for efficiency.

Having the knowledge of effectiveness of these sessions was important to be able to provide leadership with metrics 
on how successful this program is. Provider feedback via email, word of mouth, referrals and postsession surveys has proven to be not only great feedback, but also helpful with workshop marketing. The CME evaluations also helped us to verify that these sessions were useful and giving providers the training on system features that may have been forgotten when onboarding. System customization is a key feature of efficiency. EW feedback confirmed this, leading us to believe that the content was exactly what was needed to benefit providers.

\section{Limitations}

We do acknowledge the limitations of the CME data, in which neither all participants answered each question nor does it give us the amount of time saved by the provider from attending the workshop. We also acknowledge that $26 \%$ of those responding stated that they need additional information before changing practice. Also, the qualitative information relating to expressed need for additional sessions informed us that one session is likely not enough for each group.

\section{Conclusion}

Evidence has suggested that the key factors of training program success for providers using the EHR include design of the curriculum, accessible training location, staffing of the training team, and a physician champion. ${ }^{23}$ Our EW findings support this. In the future, we plan to use the EHR reporting features to evaluate efficiency before and after the EW program. As departments invest time in supporting physicians by blocking time away from clinic to attend such events, we would also like to measure a return on investment. We hope that continued efficiency workshops provide providers with tools that lead not only their satisfaction but that of patients in our organization. As an IT training team, we have learned that this is an important program that should be developed further and sustained in an effort to continue to reach as many providers as possible.

\section{Clinical Relevance Statement}

The EW program established has been found to be a successful supplement to initial EHR training for providers, especially in the presence of ongoing system change. They provide the opportunity for provider customization and improved efficiency with clinical practice and can bridge the gap that occurs with ongoing system change. These programs should be considered by IT training teams.

\section{Multiple Choice Questions}

1. Specific functionality of the electronic medical records that contribute to user burden are:

a. Data entry and discrete data elements.

b. Reporting.
c. Interoperability.
d. In-basket.
e. All of the above.

Correct Answer: The answer is option e. Evidence shows that all of these areas have created a burden for end users.

2. Outcomes of electronic medical record training for end users includes

a. Improved confidence and efficiency.

b. Revenue loss.

c. Manager dissatisfaction.

Correct Answer: The correct answer is option a. Evidence shows that improved confidence and efficiency occurs from EHR training.

Protection of Animal and Human Subjects

This manuscript discusses the development of efficiency workshops and quality improvement measures used to shape the program, thus not constituting human subjects research.

Funding

None.

Conflict of Interest

None declared.

\section{References}

1 Butcher L. A UC Davis program focuses on training to increase efficiency, ease stress associated with EHR compliance. Neurol Today 2019;19(03):41-44

2 Patt D, Stella P, Bosserman L. Clinical challenges and opportunities with current electronic health records: practicing oncologies perspectives. J Oncol Pract 2018;14(10):577-579

3 Guo U, Chen L, Mehta PH. Electronic health record innovations: Helping physicians - one less click at a time. Health Inf Manag 2017;46(03):140-144

4 Robertson SL, Robinson MD, Reid A. Electronic health record effects on work-life balance and burnout within the $\mathrm{i}^{3}$ population collaborative. J Grad Med Educ 2017;9(04):479-484

5 Harris DA, Haskell J, Cooper E, Crouse N, Gardner R. Estimating the association between burnout and electronic health record-related stress among advanced practice registered nurses. Appl Nurs Res 2018;43:36-41

6 Kroth PJ, Morioka-Douglas N, Veres S, et al. Association of electronic health record design and use factors with clinician stress and burnout. JAMA Netw Open 2019;2(08):e199609

7 Shanafelt TD, Dyrbye LN, Sinsky C, et al. Relationship between clerical burden and characteristics of the electronic environment with physician burnout and professional satisfaction. Mayo Clin Proc 2016;91(07):836-848

8 Arndt BG, Beasley JW, Watkinson MD, et al. Tethered to the EHR: Primary care physicians workload assessment using EHR event $\log$ data and time motion observation. Ann Fam Med 2017;15 (05):419-426

9 Gardner RL, Cooper E, Haskell J, et al. Physician stress and burnout: the impact of health information technology. J Am Med Inform Assoc 2019;26(02):106-114

10 Joszt L. EHR Implementation Reduces Practice Productivity, Increases Reimbursement. Available at: https://www.ajmc.com /newsroom/ehr-implementation-reduces-practice-productivityincreases-reimbursement. Accessed March 23, 2020 
11 Murphy DR, Reis B, Sittig DF, Singh H. Notifications received by primary care practitioners in electronic health records: a taxonomy and time analysis. Am J Med 2012;125(02):209.e1-209.e7

12 Murphy DR, Meyer AN, Russo E, Sittig DF, Wei L, Singh H. The burden of inbox notifications in commercial electronic health records. JAMA Intern Med 2016;176(04):559-560

13 Haidar YM, Moshtaghi O, Mahboubi H, et al. Association between electronic medical record implementation and otolaryngology productivity in the ambulatory setting. JAMA Otolaryngol Head Neck Surg 2017;143(01):20-24

14 Scott DJ, Labro E, Penrose CT, Bolognesi MP, Wellman SS, Mather RC III. The impact of electronic medical record implementation on labor cost and productivity at an outpatient orthopaedic clinic. J Bone Joint Surg Am 2018;100(18):1549-1556

15 Frogner BK, Wu X, Ku L, Pittman P, Masselink LE. Do years of experience with electronic health records matter for productivity in community health centers? J Ambul Care Manage 2017;40(01): 36-47

16 Kadish SS, Mayer EL, Jackman DM, et al. Implementation to optimization: a tailored, data-driven approach to Improve provider efficiency and confidence in use of the electronic medical record. J Oncol Pract 2018;14(07):e421-e428
17 O’Donnell A, Kaner E, Shaw C, Haighton C. Primary care physicians' attitudes to the adoption of electronic medical records: a systematic review and evidence synthesis using the clinical adoption framework. BMC Med Inform Decis Mak 2018;18(01):101

18 Rathert C, Porter TH, Mittler JN, Fleig-Palmer M. Seven years after Meaningful Use: Physicians' and nurses' experiences with electronic health records. Health Care Manage Rev 2019;44(01): 30-40

19 Greiver M, Barnsley J, Glazier RH, Moineddin R, Harvey BJ. Implementation of electronic medical records: theory-informed qualitative study. Can Fam Physician 2011;57(10):e390-e397

20 Castellucci M. One-on-one EHR training saves physician time, improves satisfaction. Mod Healthc 2018;28(38):34

21 Davis T. Creating the EMR advantage: EMR best practices study. Available at: https://klasresearch.com/report/creating-the-emradvantage/1337. Accessed March 23, 2020

22 Stevens LA, DiAngi YT, Schremp JD, et al. Designing an Individualized EHR learning plan for providers. Appl Clin Inform 2017;8 (03):924-935

23 Pantaleoni JL, Stevens LA, Mailes ES, Goad BA, Longhurst CA. Successful physician training program for large scale EMR implementation. Appl Clin Inform 2015;6(01):80-95 